\title{
Making your publications open access Resources to assist researchers and librarians
}

t has now been more than a decade since

the Budapest Open Access Initiative coined the term open access (OA) and united a movement to free scholarly literature from access barriers. Incredible progress has been made in this time with the launching of thousands of OA journals, open repositories, and mandates from institutions, funders, and various levels of government in countries around the world. The momentum only seems to be increasing in recent years. OA is now considered to be inevitable, with one prediction estimating that it will be the dominant model for scholarly literature in the next decade. ${ }^{1}$

This guide is intended to be a practical tool to help busy researchers, and the librarians who support them, make the transition to OA. The focus herein is on freely available online resources that will assist in making research publications OA; the closely associated, and rapidly growing, area of research data is beyond the scope of this column.

\section{Why should I make my publications OA?}

While most researchers are aware of the OA movement by now, there continues to be many misconceptions regarding it, as well as a lack of awareness as to the importance of OA to their own research careers. Below are some resources that provide an introduction to the movement and compelling reasons to make your publications OA.

- Open Access. This very concise and readable book is by Peter Suber, widely acknowledged to be the "de factor leader" of the OA movement and an expert on the subject. He is currently the director of the Office for Scholarly Communication at Harvard. Suber wrote this little book specifically for busy people like researchers and administrators-those who need to know about OA but are too busy to sift through the copious amounts of literature on the topic. I particularly recommend Chapter Two, where Suber provides an inventory of 15 problems with the current system of scholarly communication, and how OA has the potential to solve them. This book is, fittingly, openly available online in various formats (ePUB, Mobi, PDF, HTML). Access: http://mitpress.mit.edu/books/open-access.

- Open Access Impact Bibliography (Part of the Open Citation Project). A strategic way to convert reluctant faculty to OA may be to appeal to their desire to increase their scholarly metrics for tenure and promotion processes. Like it or not, citation counts and other metrics derived from citations, such as the h-index, matter a lot to review committees. It seems logical that publications that are openly available will have a better chance of being more widely read, and as a result cited more often... but now we have evidence that this is indeed the case. The Open Access Impact Bibliography is an ongoing list of published research that documents this "open access citation advantage." It is maintained by Steve Hitchcock of the University of Southampton. Access: http:// opcit.eprints.org/oacitation-biblio.html.

Diane (DeDe) Dawson is science liaison librarian at the University of Saskatchewan, e-mail: diane.dawson@ usask.ca

(C) 2013 Diane Dawson 
- ROARMAP. Does your institution, college, or department have a mandate requiring all members make their publications OA? Generally, when mandates are established it is big news and you'll likely have heard about it. But if you are new to your institution you may not be aware of a mandate, or you may not know the details. You can quickly check ROARMAP (Registry of Open Access Repositories Mandatory Archiving Policies) to see if your institution has a mandate and read the policy text. This is not an exhaustive list, and requires institutions register their mandates with ROARMAP, so check with your colleagues and officials to be sure. Access: http://roarmap.eprints.org/.

- SHERPA/JULIET. Increasingly, researchers are being required by their funding agencies to make the published results of their research OA. Some researchers might not be fully aware of these requirements. The best option would be to go directly to your funder's policy documentation, but it could be quite cumbersome to locate the appropri-

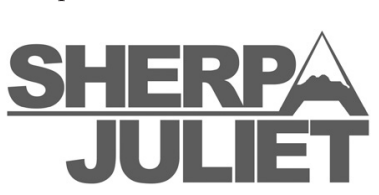
ate policy and decipher it. It is much easier to check the SHERPA/JULIET

site. This is a worldwide listing of funder's policies on $\mathrm{OA}$ publishing and archiving. You can search by country then browse the funders listed for that country, or search specifically by funder name. The record for each funder will detail their requirements for publications (and research data) and link to the actual policy itself. JULIET is part of the SHERPA services based at the Centre for Research Communications at the University of Nottingham in the United Kingdom. Access: http://www.sherpa.ac.uk/juliet/index.php.

\section{Author rights and addenda}

Authors and content creators are the copyright holders of their works unless and until they sign over these rights to a publisher. When faced with a copyright transfer agreement authors can propose modifications of the terms to the publisher thereby retaining some rights that are important to them.

\section{- Creative Commons License Chooser.}

Even if you are not seeking to publish your work in a traditional journal, you are still automatically the copyright holder of an "all rights reserved" license as the creator of the document. If you want to post your work online, and enable its reuse according to parameters of your choosing, then try the Creative Commons License Chooser. Creative Commons (CC) is a nonprofit organization that facilitates sharing of knowledge and creativity through their free legal tools. CC licenses are standardized and widely used throughout the world. The CC License Chooser will guide you through the process of selecting the license that is right for your needs. Access: http://creativecommons.org/ choose/

- Scholar's Copyright Addendum Engine. Science Commons, a former project of Creative Commons, produced this nifty addendum generator. Addenda are legal forms that authors can attach to publisher's copyright transfer agreements in order to modify them and retain certain rights. Insert the details of your manuscript into the online form, select the "Agreement Type" of your choosing, and the Addendum Engine generates a one-page legal document for you to sign. This tool is more flexible than the SPARC Author Addendum (discussed next) since it offers several options to the author related to re-use rights and timeline for access. Access: http://scholars.sciencecommons.org/

- SPARC Guide to Author Rights/ SPARC Author Addendum. This guide, created by the Scholarly Publishing and Academic Resources Coalition (SPARC), is a clear and concise introduction to the topic of author rights. It is also available as a colorful brochure in PDF (link appears in the Web page listed). Additionally, the guide links to the SPARC Author Addendum ${ }^{2}$ - a legal form that authors can print out and fill in by hand. Access: http://www.sparc.arl.org/resources /authors/addendum/.

\section{Taking the Gold Road: OA journals}

There are two main routes to OA: the "Gold" 
and the "Green" roads. The Gold Road refers to publishing in an OA outlet. Many OA journals are new, so you may not be aware of them or confident about their quality.

\section{- Directory of Open Access Journals}

(DOAJ). To find a Gold OA journal in your field the best place to start is at DOAJ. DOAJ has been in existence for a decade now and is a well-known and reputable quality-controlled list of OA journals. In order to be included in this directory, journals must be OA without an embargo, be scholarly in content, and exercise

peer-review

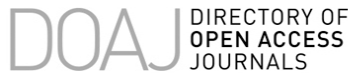
or editor/editorial board quality con-

trol (among other criteria). ${ }^{3}$ The directory may be searched or browsed by subject, country, license, or publication charges. This is not an exhaustive list since additions need to be suggested, but it is the most comprehensive free ${ }^{4}$ listing of OA journals available. Libraries can support the ongoing work of the DOAJ by registering for a membership. Access: http:// www.doaj.org/.

- Open Access Scholarly Publishers Association (OASPA). Another way to assess the quality of an unfamiliar OA publisher is by checking to see if they belong to the Open Access Scholarly Publishers Association (OASPA). OASPA advocates and promotes Gold OA publishing on behalf of its members. It is in their interest to ensure high standards in this industry. Members of OASPA are expected to adhere to a Professional Code of Conduct that would exclude any disreputable publishers. Access: http://oaspa.org/.

- Scholarly Open Access. The dark side of Gold OA is the recent proliferation of scam publishers seeking to exploit the "author pays" economic model of OA for their own gain. These outlets attempt to lure unsuspecting researchers by spamming them with calls for papers. They often have little or no peer-review process, and simply exist to make money from collecting author's fees or by serving as vanity presses for unscrupulous authors. Jeffrey Beall, librarian at the University of ColoradoDenver, has made it his mission to document and expose these "predatory" publishers on his Scholarly Open Access blog. He maintains a list of questionable publishers and journals on this site. It is always wise to thoroughly investigate any unfamiliar publisher before submitting your manuscripts to them; this applies equally for subscription or OA publishers. Ask your colleagues about the title and check DOAJ, OASPA, and the Scholarly Open Access blog. Access: http://scholarlyoa.com/.

\section{The "hybrid" OA option}

- Publishers with Paid Options for Open Access (SHERPA/RoMEO). A new option for authors has emerged in recent years: the "hybrid journal." Hybrid journals are traditional subscription journals that offer authors the option of making their individual articles OA for a fee. Many well-known publishers offer this now. The SHERPA folks at the University of Nottingham maintain this list of hybrid publishers, the name of their hybrid programs, and the author's fee involved. You can also link out to each publisher's site for more information. Access: http://www. sherpa.ac.uk/romeo/PaidOA.html.

\section{Taking the Green Road: OA repositories}

Have you already published in a traditional subscription journal? Already signed away your copyright to the publisher? You can (often) retroactively make your work OA by taking the Green Road of "self-archiving": posting a copy of the article in an open online repository. Archiving your publications in a repository, as opposed to simply posting on your departmental Web site, ensures that they are more effectively indexed by academic search engines.

\section{What are your rights to self-archive?}

- SHERPA/RoMEO. The first thing to do is dig up that old copyright transfer agreement to see what rights you retain for selfarchiving. The majority of publishers permit authors to post certain versions of their manuscripts in open repositories-usually the postprint (author's final version, after peer-review but before typesetting). It is 
also important to discover if your publisher imposed an embargo period on posting, or if there are any other restrictions. Can't find your copyright transfer agreement? Check the SHERPA/RoMEO site. RoMEO is a directory of publisher's policies on author self-archiving. Search for the journal that you published in by title or ISSN. The record for each journal title will clearly explain your self-archiving rights and link out to documentation from the publisher. RoMEO is maintained by the University of Nottingham in the United Kingdom. Access: http://www.sherpa.ac.uk/romeo/.

\section{Repository directories}

- OpenDOAR. Once you have determined if you are able to post your article, and which version, then you need to find a repository to archive it. Many institutions now have institutional repositories (IRs) and staff that will assist you in archiving your work, but if you don't have access to an IR, then a subject reposito-

\section{OpenDOAR ${ }^{\text {ti is a lio }}$ OpenDOAR www.opendoar.org Ope n -}

DOAR is an authoritative directory of OA repositories (both IRs and subject repositories). Each repository has been visited by OpenDOAR staff to ensure the accuracy of the information listed in the directory. You can browse a list of repositories by country or search for one in a given subject area. There are currently 250 subject/disciplinary repositories listed in OpenDOAR. This is yet another useful resource out of the University of Nottingham, United Kingdom. Access: http:// www.opendoar.org/find.php.

\section{Multidisciplinary repositories}

- figshare. figshare is a popular option for posting research results in any subject area and in many different file formats. Although primarily intended to be a home for research results not traditionally disseminated (e.g., datasets, figures, media, negative results), figshare is also being used by many researchers to post copies of publications, presentations, and posters. The main benefit of figshare is that it is very simple to use and makes your work discoverable and easily citable for users. Researchers can upload an unlimited amount of content to their public space. Access: http:// figshare.com/.

- OpenDepot.org. OpenDepot was established to ensure that researchers at institutions without IRs have a place to deposit their publications. OpenDepot will automatically detect if your institution has an IR (if you are on campus when you visit their Web site) and will redirect you to that repository. If your institution subsequently establishes an IR, then OpenDepot will transfer items to the new repository. This service is maintained by the EDINA organization at the University of Edinburgh, United Kingdom. Access: http:// opendepot.org/.

- Zenodo. This recently launched (May 2013) multidisciplinary repository is intended to share and showcase all research outputs not already posted in subject or institutional repositories. Zenodo is a project of OpenAIRE, the organization established to support and implement OA in Europe, but is open to all researchers anywhere in the world. Zenodo uses the same cloud infrastructure as the research output from CERN's Large Hadron Collider that is to say that the repository software is well-tested and your documents will be safe. Access: http://zenodo.org/.

\section{Notes}

1. David W. Lewis, "The Inevitability of Open Access, " College and Research Libraries 73, no. 5 (2012): 493-506, http://crl.acrl.org/content /73/5/493.abstract (accessed August 20, 2013).

2. Also see the SPARC Canadian Author Addendum adapted to reflect Canadian copyright law: http://www.carl-abrc.ca/uploads /pdfs/EngPubAgree.pdf

3. DOAJ recently revised their selection criteria, see www.doaj.org/doaj?func=news $\& n I d=303 \&$ uiLanguage $=$ en .

4. Ulrich's Periodical Directory is another option, but it is a subscription product. You can retrieve a list of OA journals by limiting your search to the "Key Feature" of OA (under the Advanced Search field). $\boldsymbol{n}$ 